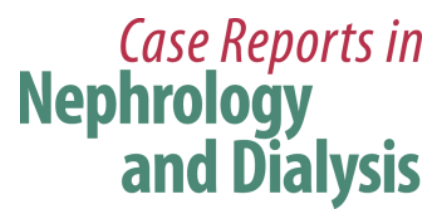

Case Rep Nephrol Dial 2018;8:253-260

DOI: 10.1159/000494716

Published online: November 27, 2018

(C) 2018 The Author(s)

Published by S. Karger AG, Basel

www.karger.com/cnd

This article is licensed under the Creative Commons Attribution-NonCommercial 4.0 International License (CC BY-NC) (http://www.karger.com/Services/OpenAccessLicense). Usage and distribution for commercial purposes requires written permission.

\title{
A Case of Rapid Progressive Kidney Dysfunction with Severely Calcified Stenotic Aorta
}

\author{
Makoto Harada a, b Yusuke Miyashita ${ }^{c}$ Tohru Ichikawa ${ }^{a}$ \\ Mamoru Kobayashia
}

aDepartment of Nephrology, Nagano Red Cross Hospital, Nagano, Japan; ${ }^{b}$ Department of Nephrology, Shinshu University School of Medicine, Matsumoto, Japan; 'Department of Cardiology, Nagano Red Cross Hospital, Nagano, Japan

\section{Keywords}

Coral reef aorta · Stenotic anastomosis · Endovascular therapy

\begin{abstract}
Coral reef aorta is rare type of atherosclerotic diseases with severe calcification in the visceral part of the aorta. We present a case of coral reef aorta with severe abdominal aortic stenosis in a 67-year-old man. The patient presented with hypertension, claudication, and rapid progression of renal dysfunction over several months. Angiography revealed a severely stenotic suprarenal abdominal aorta resulting in renal ischemia and dysfunction. In addition, his right kidney was completely atrophied. After open surgical repair of the stenotic aorta including renal artery reconstruction, renal function did not improve. There was stenotic anastomosis to the renal artery. After endovascular therapy to the stenotic anastomosis, renal function dramatically improved. Stenotic coral reef aorta may be the cause of kidney dysfunction. In addition, surgical complication of stenotic anastomosis may be successfully treated by endovascular therapy.

(C) 2018 The Author(s)

Published by S. Karger AG, Basel
\end{abstract}




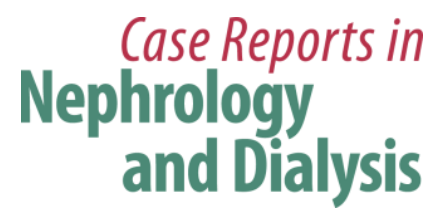

Case Rep Nephrol Dial 2018;8:253-260

DOI: 10.1159/000494716

(c) 2018 The Author(s). Published by S. Karger AG, Base www.karger.com/cnd

Harada et al.: A Case of Rapid Progressive Kidney Dysfunction with Severely Calcified Stenotic Aorta

\section{Introduction}

Atherosclerotic diseases are often observed in elderly patients with a history of smoking, diabetes mellitus, hypertension, and hyperlipidemia. However, atherosclerotic diseases with severe calcification in the visceral part of the aorta, termed coral reef aorta (CRA), are rare [1, 2]. CRA is often complicated by renovascular hypertension, claudication, visceral ischemia, and blue toe syndrome [2]. Most patients with symptomatic CRA undergo surgical treatment.

Deterioration of renal function after aortic reconstructive surgery, including renal artery reconstruction, is common in patients with aortic aneurysm [3]. Although the cause of renal dysfunction has been attributed to intraoperative temporal renal ischemia, it is possible that stenotic anastomosis to the renal artery causes chronic renal ischemia, resulting in deteriorating renal function. However, cases of renal dysfunction due to stenotic anastomosis to the renal artery after aortic reconstruction surgery are rarely reported.

Here, we report a case of CRA with severe suprarenal abdominal aortic stenosis resulting in rapidly progressive renal dysfunction. The patient underwent aortic reconstruction surgery with reconstruction of the renal artery. However, postoperatively, stenotic anastomosis to the renal artery caused renal ischemia resulting in deterioration of renal function. Renal dysfunction was improved by endovascular therapy (EVT) to the renal artery stenotic anastomosis.

\section{Case Report}

A 67-year-old Japanese man with hypertension, hyperlipidemia, and a history of smoking presented with claudication and leg numbness. He had no history of diabetes mellitus. His ankle brachial index (ABI) was low at 0.48 (right)/0.51 (left). Abdominal aortic bruit was audible in the epigastrium of the umbilicus area. Carotid and femoral bruits were not audible. Bilateral dorsal and dorsalis pedis arteries were impalpable. Computed tomography revealed that his whole aorta was severely calcified, and aortic arch aneurysm, infrarenal abdominal aortic aneurysm, and left internal iliac artery aneurysm were detected. Furthermore, suprarenal abdominal aortic stenosis with severe calcification was identified (Fig. 1a). The root of his right renal artery was totally occluded, and his right kidney was atrophied; the left kidney was not atrophic (Fig. 1b). His clinical course is presented in Figure 2. His initial serum creatinine ( $\mathrm{sCr}$ ) level was $1.97 \mathrm{mg} / \mathrm{dL}$, but increased within 2 months. He was admitted to the hospital based on the suspicious of decreased renal blood flow leading to rapid progression of kidney dysfunction. On admission, his $\mathrm{sCr}$ was $4.83 \mathrm{mg} / \mathrm{dL}$. Urinary examination revealed that proteinuria was $\pm 0.24 \mathrm{~g} / \mathrm{gCr}$, and hematuria was not detected (main laboratory data are shown in Table 1). Aortic and renal artery angiography was performed. There was severe suprarenal abdominal aortic stenosis; no significant stenotic lesion was detected in his left renal artery. The pressure gradient at the stenotic aorta was approximately $60 \mathrm{~mm} \mathrm{Hg}$. These results indicated that severe aortic stenosis caused renal ischemia, resulting in deteriorating renal function. Percutaneous plain balloon angioplasty was done with $8.0 / 40$ and $10.0 / 40 \mathrm{~mm}$ balloons. After EVT to the stenotic aorta, his renal function was temporarily improved, but later worsened because of dehydration, the use of an angiotensin receptor blocker (ARB), and severe anemia. He required hemodialysis for a short period. After the dehydration and anemia were improved, and ARB was discontinued, his renal function stabilized with an $\mathrm{sCr}$ of 


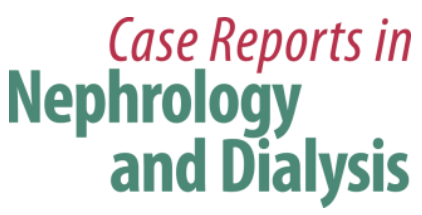

\begin{tabular}{l|l} 
Case Rep Nephrol Dial 2018;8:253-260 \\
\hline DOI: 10.1159/000494716 & $\begin{array}{l}\text { @ } 2018 \text { The Author(s). Published by S. Karger AG, Basel } \\
\text { www.karger.com/cnd }\end{array}$
\end{tabular}

Harada et al.: A Case of Rapid Progressive Kidney Dysfunction with Severely Calcified Stenotic Aorta

approximately $2.0-2.5 \mathrm{mg} / \mathrm{dL}$. Six months from his first admission to our hospital, reconstructive surgery to the suprarenal abdominal aortic stenosis and infrarenal abdominal aortic aneurysm was performed. The abdominal aorta was replaced with a $24-\mathrm{mm}$ ( 4 branched J Graft, Japan Lifeline, Japan) and 20-mm (bifurcated J Graft, Japan Lifeline) artificial grafts. The celiac artery, superior mesenteric artery, and left renal artery were reconstructed with an artificial graft, while the bilateral internal iliac artery and right renal artery were sacrificed. After the operation, $\mathrm{sCr}$ was temporarily decreased at $1.69 \mathrm{mg} / \mathrm{dL}$, but renal dysfunction progressed again after 3 weeks (sCr level $3.20 \mathrm{mg} / \mathrm{dL}$ ). Because echography and computed tomography indicated stenotic anastomosis to his left renal artery, EVT to the anastomosis of the renal artery was performed. A 6.0/18 mm Palmaz Genesis (Cardinal health company, Japan) stent and a 3.5/18 mm BMX-J (Biosensors, Japan) stent were implanted via left radial artery (Fig. 1c-f). After EVT, his renal function markedly improved and his sCr level was $1.06 \mathrm{mg} / \mathrm{dL}$. Urinary protein was not significantly increased after EVT. His blood pressure was decreased, and he did not require any blood pressure-lowering agents. His renal function has been preserved with an sCr of approximately $1.0 \mathrm{mg} / \mathrm{dL}$ for 6 months.

\section{Discussion}

Here, we report a case of CRA with severe visceral aortic calcification and stenosis. It was thought that the patient possibly had a preexisting renal injury. Because he had a history of smoking, hypertension, and hyperlipidemia, and he presented poor urinary abnormalities, it was also thought that he possibly had nephrosclerosis with hypertensive arterial sclerosis or ischemic tubulointerstitial nephropathy concomitant with atherosclerosis of the renal arteries. In cases involving several atherosclerotic risk factors, dorsalis pedis arteries and evaluating ABI value may need to be examined. "Bilateral" abnormalities such as impalpable dorsalis pedis arteries and severely decreased ABI may suggest aortic stenosis. In the clinical course of the current case (Fig. 2), renal function was exacerbated after aortic balloon therapy. Contrast agents used for angiography, enhanced vascular resistance in response to the increased renal blood supply after ballooning, and re-stenosis after EVT might have been involved in the acute decline of the kidney function.

The frequency of CRA is rare $[1,2]$. Previous studies reported that $0.6-1.8 \%$ of patients with atherosclerotic diseases are diagnosed with CRA [2]. The mean age of patients with CRA is 59.5 years old, younger than that of patients with common arterial occlusive diseases such as angina, peripheral arterial diseases, and cerebral infarction [2]. In the current case, although the patient had severe calcification and a stenotic lesion in his visceral aorta, other arterial occlusive diseases were not detected. We evaluated his carotid and intracranial arteries by performing ultrasonography and magnetic resonance imaging (MRI). Cervical ultrasonography revealed that there was slight calcified plaque in the left common carotid artery, but a significant stenotic lesion or severe intima-media thickness was not detected. MRI also revealed no significant stenotic lesions in his intracranial arteries, carotid arteries, or vertebral arteries. In addition, myocardial ischemia was not suspected by coronary computed tomography angiography and myocardial perfusion imaging with thallium-201. Thus, the clinical characteristics and etiology of CRA may be different from common atherosclerotic diseases. The detailed mechanisms of the development of CRA remain uncertain [1-4]. A previous study 


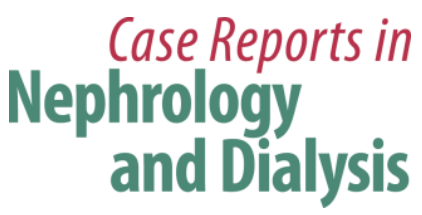
\begin{tabular}{l|l} 
Case Rep Nephrol Dial 2018;8:253-260 \\
\hline DOI: 10.1159/000494716 & $\begin{array}{l}\text { @ 2018 The Author(s). Published by S. Karger AG, Basel } \\
\text { www.karger.com/cnd }\end{array}$ \\
\hline
\end{tabular}

Harada et al.: A Case of Rapid Progressive Kidney Dysfunction with Severely Calcified Stenotic Aorta

investigated serum calcification markers and aortic tissue in patients with CRA [4]. Serum uncarboxylated matrix gla protein (ucMGP) and fetuin-A in patients with CRA were markedly lower than those in the healthy control group [4]. In addition, ucMGP and fetuin-A were identified in the calcified lesion from the aorta based on immunohistochemical staining [4]. Electron microscopy revealed that multiple foci of calcification and fine crystal structures were detected in the calcified aorta, resulting in the formation of hydroxyapatite [4]. ucMGP and fetuin-A suppress calcification, and in particular, fetuin-A inhibits the formation of hydroxyapatite by binding the complex of calcium and phosphorus [5]. Thus, these factors may be associated with the development of CRA.

Surgical treatment is often performed due to the various symptoms associated with CRA. With regard to symptoms due to CRA, a previous study of 70 CRA cases reported by Grotemeyer et al. [2] indicated that, because CRA often causes renal artery stenosis and/or suprarenal aortic stenosis, $40.0 \%$ of CRA cases presented with renovascular hypertension resulting in severe headache. Claudication was observed in $38.6 \%$ of patients, and symptoms due to visceral ischemia were observed in $21.4 \%$ of patients [2]. In the current case, the patient presented not only with hypertension and claudication, but also acute deterioration of kidney function. A few previous cases of rapid progression of renal dysfunction due to CRA have been reported [6,7]. One case reported by Blay and Zhou [6] was treated by aorta endarterectomy, and another case reported by Bowman et al. [7] was treated with thromboendarterectomy. The case reported by Blay and Zhu [6] showed rapidly improved renal function. The case reported by Bowman et al. [7] required a short period of dialysis, but ultimately the patient discontinued dialysis and remained dialysis independent. Thus, the renal function of both previous cases was improved by surgical treatment alone. However, our patient did not show continuous improvement of renal function after surgical treatment. In the current case, the patient required surgically treatment with abdominal aortic reconstruction, visceral aortic branches' reconstruction, and left renal artery reconstruction using artificial grafts. Although his kidney function temporarily improved after the operation, his renal function deteriorated again after 3 weeks. A previous study demonstrated that open repair of abdominal aortic aneurysm, including renal artery reconstruction, is associated with the development of complications and requirement of dialysis [3]. In the current case, his right renal artery had been totally occluded, and his right kidney was deteriorated as well as atrophied. In addition, severe stenotic anastomosis to the left renal artery caused renal ischemia, resulting in severe renal dysfunction. Our case was different from the previous 2 reported cases (Blay et al. and Bowman et al.) because of the requirement for renal artery reconstruction [6, 7]. Fortunately, his renal function was dramatically improved by EVT with anastomosis to the left renal artery. Similar cases have been scarcely reported.

In conclusion, stenotic CRA may be one of the causes of rapid progression of kidney dysfunction. In addition, there is a high risk of renal dysfunction requiring dialysis after surgery to the abdominal aorta including renal artery reconstruction. EVT to the renal artery anastomosis may be effective for improvement in renal dysfunction. 


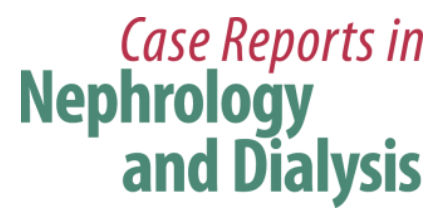

\begin{tabular}{l|l}
\hline Case Rep Nephrol Dial 2018;8:253-260 \\
\hline DOI: 10.1159/000494716 & $\begin{array}{l}\text { (c) 2018 The Author(s). Published by S. Karger AG, Basel } \\
\text { www.karger.com/cnd }\end{array}$
\end{tabular}

\section{Statement of Ethics}

The present case report adhered to the Declaration of Helsinki, and informed consent for publication was obtained from the patient.

\section{Disclosure Statement}

The authors declared no conflict of interest.

\section{References}

1 Qvarfordt PG, Reilly LM, Sedwitz MM, Ehrenfeld WK, Stoney RJ. “Coral reef” atherosclerosis of the suprarenal aorta: a unique clinical entity. J Vasc Surg. 1984 Nov;1(6):903-9.

2 Grotemeyer D, Pourhassan S, Rehbein H, Voiculescu A, Reinecke P, Sandmann W. The coral reef aorta - a single centre experience in 70 patients. Int J Angiol. 2007;16(3):98-105.

3 Wooster M, Back M, Patel S, Tanious A, Armstrong P, Shames M. Outcomes of concomitant renal reconstruction during open paravisceral aortic aneurysm repair. J Vasc Surg. 2017 Oct;66(4):1149-56.

4 Schlieper G, Grotemeyer D, Aretz A, Schurgers LJ, Krüger T, Rehbein H, et al. Analysis of calcifications in patients with coral reef aorta. Ann Vasc Surg. 2010 Apr;24(3):408-14.

5 Kuro-o M. Klotho, phosphate and FGF-23 in ageing and disturbed mineral metabolism. Nat Rev Nephrol. 2013 Nov;9(11):650-60.

6 Blay E Jr, Zhou W. Rapid renal function deterioration: an unusual presentation of coral reef plaque. Ann Vasc Surg. 2014 Jan;28(1):260.e13-6.

7 Bowman BT, Bernhard MR, Ibidapo AA, Okusa MD. Acute kidney injury due to 'coral reef syndrome'. Kidney Int. 2013 Jan;83(1):182. 

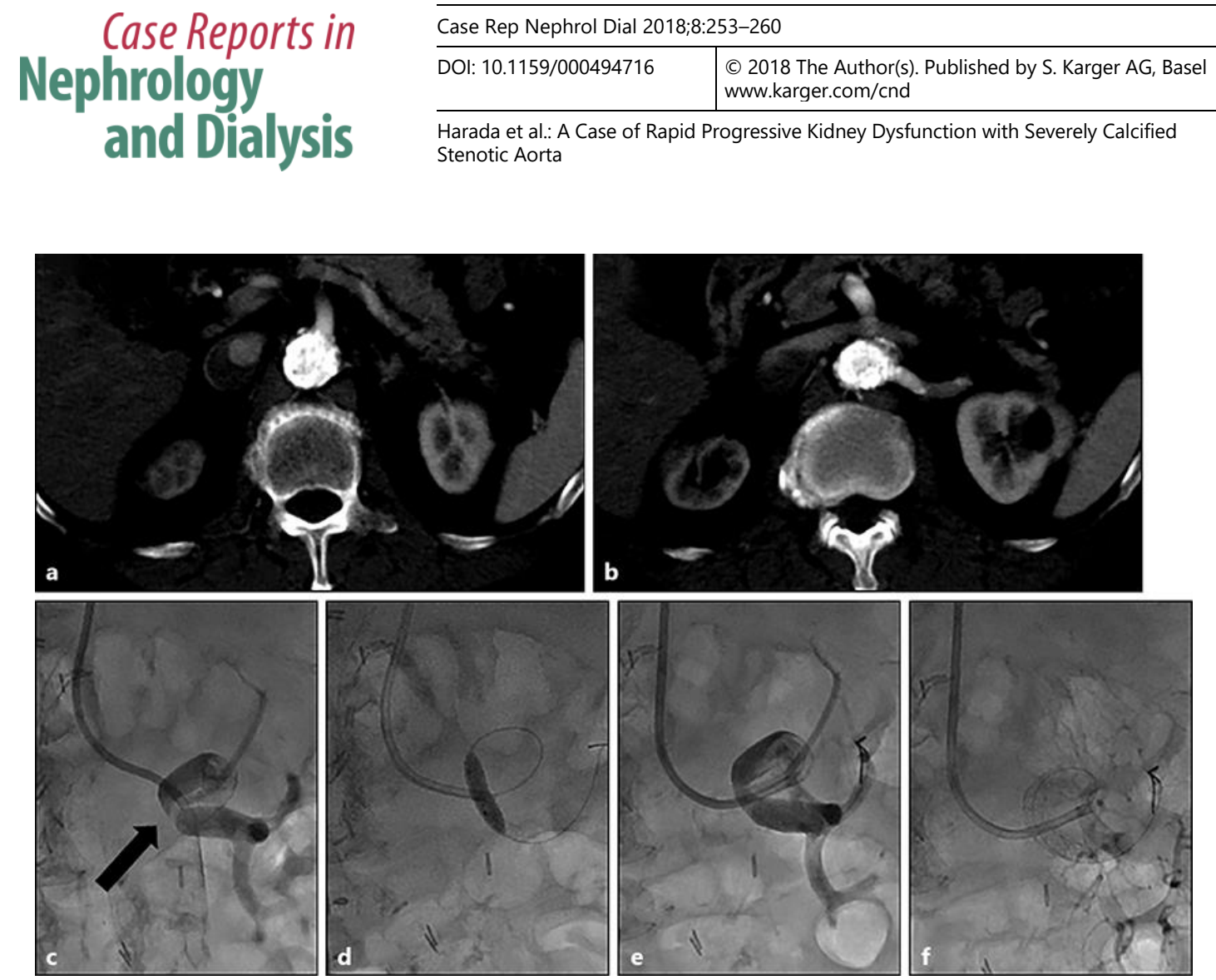

Fig. 1. Contrast-enhanced computed tomography findings. a Severe calcification and stenosis were observed in the lumen of the aorta. The right kidney was atrophic. $\mathbf{b}$ The root to middle part of the left renal artery and left kidney showed good contrast. a, b The root of the right renal artery was not detected, indicating right renal artery occlusion. Endovascular therapy (EVT) to the anastomosis to the renal artery was performed. c Stenotic anastomosis to the left renal artery was detected (arrow). d A stent was placed to the anastomosis of the left renal artery. After EVT, the stenotic lesion was improved (e) and the entire kidney showed good contrast (f). 


\section{Case Reports in Nephrology and Dialysis}

www.karger.com/cnd

Harada et al.: A Case of Rapid Progressive Kidney Dysfunction with Severely Calcified Stenotic Aorta

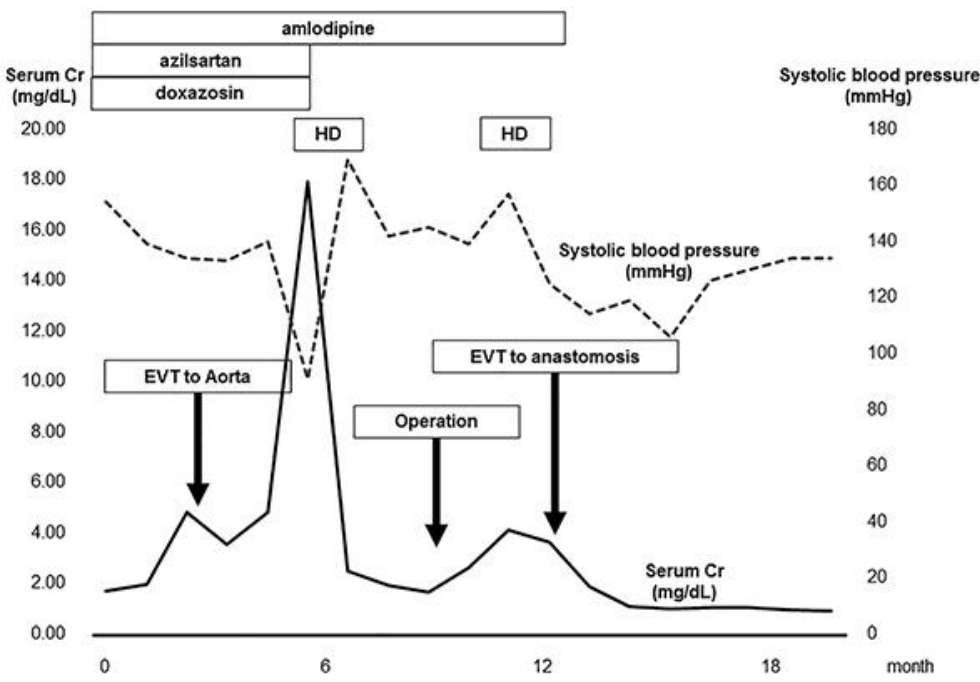

Fig. 2. Clinical course of the current case. Cr, creatinine; EVT, endovascular therapy; HD, hemodialysis. 


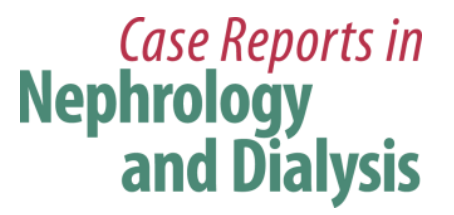

Case Rep Nephrol Dial 2018;8:253-260

(C) 2018 The Author(s). Published by S. Karger AG, Basel www.karger.com/cnd

Harada et al.: A Case of Rapid Progressive Kidney Dysfunction with Severely Calcified Stenotic Aorta

Table 1. Main laboratory data

\begin{tabular}{|c|c|c|c|}
\hline Urinanalysis & & T. chol & $180 \mathrm{mg} / \mathrm{dL}$ \\
\hline Protein & $0.24 \mathrm{~g} / \mathrm{gCr}$ & HDL-c & $62 \mathrm{mg} / \mathrm{dL}$ \\
\hline Hematuria & $1-4 / \mathrm{HPF}$ & LDL-c & $107 \mathrm{mg} / \mathrm{dL}$ \\
\hline NAG & $16.2 \mathrm{U} / \mathrm{L}$ & $\mathrm{TG}$ & 93 mg/dL \\
\hline$\beta 2 \mathrm{MG}$ & $164 \mu \mathrm{g} / \mathrm{L}$ & AST & $11 \mathrm{U} / \mathrm{L}$ \\
\hline Blood analysis & & ALT & $12 \mathrm{U} / \mathrm{L}$ \\
\hline WBC & $4,200 / \mu \mathrm{L}$ & $\mathrm{LDH}$ & $183 \mathrm{U} / \mathrm{L}$ \\
\hline Neut & $54.3 \%$ & ALP & $187 \mathrm{U} / \mathrm{L}$ \\
\hline Lym & $33.1 \%$ & $\gamma \mathrm{GT}$ & $22 \mathrm{U} / \mathrm{L}$ \\
\hline Mono & $7.6 \%$ & T. bil & $0.4 \mathrm{mg} / \mathrm{dL}$ \\
\hline Eos & $4.5 \%$ & CK & $78 \mathrm{U} / \mathrm{L}$ \\
\hline Baso & $0.5 \%$ & $\mathrm{HbA1c}$ & $5.7 \%$ \\
\hline $\mathrm{Hb}$ & $11.6 \mathrm{~g} / \mathrm{dL}$ & ANA & $\times 20$ \\
\hline Plt & $14.1 \times 10^{4} / \mu \mathrm{L}$ & (Homogeneous pattern) & \\
\hline Total protein & $7.6 \mathrm{~g} / \mathrm{dL}$ & Anti-dsDNA antibody & negative \\
\hline Albumin & $4.6 \mathrm{~g} / \mathrm{dL}$ & $\mathrm{C} 3$ & $74 \mathrm{mg} / \mathrm{dL}$ \\
\hline BUN & $55.3 \mathrm{mg} / \mathrm{dL}$ & $\mathrm{C} 4$ & $35 \mathrm{mg} / \mathrm{dL}$ \\
\hline $\mathrm{Cr}$ & $4.83 \mathrm{mg} / \mathrm{dL}$ & CH50 & $51.7 \mathrm{U} / \mathrm{mL}$ \\
\hline UA & $7.4 \mathrm{mg} / \mathrm{dL}$ & MPO-ANCA & negative \\
\hline $\mathrm{Na}$ & $130 \mathrm{mEq} / \mathrm{L}$ & PR3-ANCA & negative \\
\hline $\mathrm{K}$ & $5.3 \mathrm{mEq} / \mathrm{L}$ & Anti-GBM antibody & negative \\
\hline $\mathrm{Cl}$ & $96 \mathrm{mEq} / \mathrm{L}$ & & \\
\hline $\mathrm{Ca}$ & $9.2 \mathrm{mg} / \mathrm{dL}$ & & \\
\hline
\end{tabular}

